\title{
Scientific and Common Sense Reasoning: A Comparison
}

\author{
DONELSON R. FORSYTH \\ Virginia Commonwealth University
}

An ethnomethodological approach to human activity focuses on how members accomplish some sense of orderly reality through interpretive creation. Moving from a flexible theoretical base made possible by the radical epoque and its suspension of a given, fixed reality with attendent features such as subject-object dualism, perceptual processing, and nonreciprocal causal sequences, the ethnomethodologist argues that all reality, rather than being merely perceived, must be constructed by the member via certain standard methods and practices. While not necessarily at odds with other contemporary approaches such as social psychology's attribution theory (Heider, 1958) and recent work in cognitive psychology (e.g., Neisser, 1967), the stress that is placed on the denial of perceived reality as given makes ethnomethodology an information "doing" model rather than an information processing one.

This central concern with reality construction shifts the emphasis to how members accomplish meanings and information rather than what reality is done. Of particular interest are the empirically verifiable ways in which people accomplish meanings through the construction of a reality which organizes and "glosses" inconsistencies in the observed phenomena of the world. Individuals' accounts of their social environment are viewed as situational accomplishments which permit the member to come to understand and recognize the underlying basis of reality, enabling easy and adequate functioning in social interactions. Most important are the "demonstrably rational properties of indexical expressions and indexical actions [as] an ongoing achievement of the organized activities of everyday life" (Garfinkel, 1967) and the several methods/practices which have been recognized as essential for the construction of mundane reality.

As Garfinkel (1967) suggests, one of the fundamental means by which individuals make sense of the world in creating a common sense knowledge of reality is the documentary method of interpretation.

The method consists of treating an actual appearance as "the document of" as "pointing to," as "standing in behalf of" a presupposed underlying pattern. Not only is the pattern 
derived from its individual documentary evidences but the individual evidences, in their turn, are interpreted on the basis of "what is known" about the underlying pattern. Each is used to elaborate the other. (p. 78)

As this definition makes explicit, the documentary method is a dynamic, reciprocally balanced interaction between indexical particulars (the "evidences" which are used to create, and are created by, social reality) and the constructed underlying explanation done by the member. Garfinkel (1963, 1967) and other ethnomethodologists (e.g., Cicourel, 1973; Leiter, 1976) also enumerate several practices or procedures that provide the substance of the documentary method. One is the assumption of reciprocity of perspectives, which entails proceeding as if physical and social location are largely irrelevant to the perceptually bound processing of information. Quite logically, the member assumes that the interpreted world is an objectively knowable reality - the only reality - and so concludes that it is "perceived" veridically, passively, and without interpretation. From this assumption, it further follows that others present must also be experiencing similar perceptions largely determined by the properties of these highly factual phenomena.

Another procedure is the doing of a normal form, which is the accomplishment of a common sense principle which provides that member with "instructions for unwittingly (and sometimes deliberately) evaluating and striving for a reciprocally assumed normal form judgement" of discrepancies or ambiguities which may appear (Cicourel, 1973, p. 86). The third procedure, or group of procedures involves the implementation of adhocing practices such as the et cetera clause, the let it pass principle, and a retrospective-prospective sense of occurrence. The et cetera clause is the central practice in this group. It is the means by which individuals fill in meanings "throughout the exchange and after the exchange when attempting to recall or reconstruct what happened because of the inadequacies of oral and non-oral communication, and the routine practice of leaving many intentions unstated"(Cicourel, 1973, p. 87). Thus, the et cetera clause relies on the "let it pass" principle since unclear information is allowed to drop from consideration if it does not add to the understanding of the constructed gloss of the situation, the doing of indexical particulars reflexively, and the retrospective-prospective sense of occurrence filling in before, during, and after the activity.

Examination of the scope of the practices and procedures enumerated by ethnomethodologists suggests that these activities alone are not sufficient to account for (1) all the rational properties of common sense activity as suggested by Garfinkel (1967) or Schutz (1953), and (2) the many features of mundane reality documented by Mehan and Wood (1975). Some other features of sense-making have been neglected. However, these features, while 
overlooked and therefore never systematically examined, have been hinted at in various sources. Several recent philosophies of science suggest that scientific reasoning is, in essence, an extension of everyday reasoning processes. For example, Polanyi $(1974$, p. 66$)$ builds the strong case that science "can never be more than an affirmation of the things we belive in," and catalogues some of the self-preserving features of implicit belief systems (Polanyi, 1962). Garfinkel has also noted that common-sense activity and scientific activity share several apparently rational properties. Both common sense and scientific members are prone to categorization and comparison in order to form typifications and understand new situations on the basis of other situations. Both admit to a degree of "tolerable error" by which the suggested explanation or reality constructed is allowed to vary, or to fall somewhat at odds with the indexical particulars accomplished. Also, both "search for the means" to achieve an understanding of the constructed situation, and this necessarily involves the use of procedures that have worked well in the past. Other common sense and scientific reasoning practices such as the selection of strategies ("what-to-do-in-case-of's") concern timing, prediction, rules of procedure, and choice between schemata and its grounds are suggested by Garfinkel, and while many of the aforementioned and defined practices are clearly evident in these types of rational operations, they do not account for all of this construction.

Similarly, the features of mundane reality listed by Mehan and Wood (1975) cannot be totally supported by these practices alone. The assumed facticity of the constructed reality, so essential to the documentary method, must somehow be accomplished. The allocation of existential import to indexical particulars is a prime feature of mundane realities, and the practice must be dealt with ethnomethodologically. In addition, the development of the stock of common taken-for-granted knowledge with its assumptions and normal forms is supported by the doing of the documentary method, but it cannot rely solely on that practice. An underlying, implicit, but as yet unexplicated practice or method is necessary to account for this establishment of facticity and the stock of assumptions about the world.

\section{THE METHOD OF REALIZATION}

The method of realization, as employed in the constructive doing of members, is suggested to account for the facticity of the indexical particulars created and the underlying stock of knowledge that they both generate and are generated by. Just as in science where any set of findings can be explained with an infinite number of hypotheses, so a person can account for the indexical particulars he creates with multiple realities. However, because of the member's belief in the facticity and uniqueness of reality, usually only one 
specific explanation is completely embraced by the member, and this account is taken to represent truth-the actual way the world exists, the correct description of the situation. For example, the individual in an elevator can account for his ability to move from one floor to another with a variety of explanations. However, in all likelihood the member will believe that taking an elevator enables one to reach another floor, because the elevator itself moves up and down, and not, for example, because the building moves while the elevator remains stationary. Similarly, our member thinks objects cling to the surface of the earth because of the difficult to comprehend but scientifically reputable force known as "gravity," and not because of some magical attraction. Thus, the unexplained becomes the explained, and so leaves behind its uncertain status as a part of the greyish area between the real and the imaginary; until the member can explain it, he cannot be certain that it is "real."

The method of realization is thus concerned with how members define the difference between what is a reasonable construction given the particulars, stock of knowledge, and assumptions, and what is an unreasonable, irrational construction given the same particulars, stock of knowledge, and assumptions. In constructing an explanation, the member intuitively takes advantage of the same interpretative techniques as a physician diagnosing an illness, a scientist attempting to account for an anomalous result, or a science-fiction buff gathering evidence for the existence of visitors from outer space. For example, the physician's reality problems center around accomplishing some kind of medically valid explanation for a group of symptoms. Understandably (but unfortunately, for the physician), in many cases the symptoms that the physician "recognizes" in the patient do not perfectly match up with any of the already established illnesses with which the doctor is familiar. By continued interpretive work, however, the doctor will eventually reach an understanding of the illness, largely through the implementation of normal forming and letting inexplicable incidentals pass. Indeed, in Bloor's (1976) documentation of the reasoning of physicians assessing the need for adenotonsillectomy, it is clear that doctors reach disparate conclusions because they are using different normal forms and examination routines.

Once the physician has made his or her diagnosis, the problem is solved, and the symptoms which at one time seemed difficult to reconcile with one another fit neatly into place. Further, even if an explanation cannot be obtained immediately, the doctor will prefer to gather additional information and suspend any judgment rather than accepting certain types of explanations. For example, if the doctor cannot explain a certain configuration of symptoms that seems particularly bizarre, it is unlikely that he would be willing to accept an explanation that the illness was caused by a hex put on the patient or voodoo. Instead, some other explanation that meets the criterion of rationality for the doctor is sought to account for the observed particulars; if 
none is available, the doctor would prefer to not know the exact origin of the disease than to know that it has, say, supernatural origins.

Similarly, the member of a society does not construct just any explanation for the phenomena of the world, but instead-like the physician-develops an explanation that defines the constructed particulars in an "isolatable, typically rational, i.e., coherent, or consistent, or chosen, or planful, or effective, or methodical, or knowledgeable manner"(Garfinkel, 1968, p. 32). The constructor's purpose is to decide what formulation the indexical particulars reflexively support, and which alternative explanations are unsupported or demonstrably irrational. The constructor does several explanations of the indexical particulars, and these alternative explanations must be narrowed down to a single explanation that best accounts for the particulars and information accomplished within a given scene. It is this selection process that relies on the method of realization for its fulfillment, since it and its incumbent procedures establish the taken-for-granted rules-ofcorrespondence between particulars and interpretive schemata and guarantee the facticity of constructed reality.

In realizing, the constructor is interested in two basic products. The first is the reflexive confirmation and selection of an account for the indexical particulars, and the second is the accomplishment of concrete, existential import for the created particulars and accounts. What the member proceeds to do is employ an assumed-to-be-accurate and general set of practices to determine which schemata are supported or confirmed by any given indexical particulars. This is not to say that the particulars and schemata will not be reflexively accomplished as one affects the accomplishment of the other, but additional interpretive work will be required to determine which realizations are rational and demonstrably valid. As Goodman (1973) suggests, the individual member is assumed to be "in motion from the start, striking out with spontaneous predictions in dozens of directions, and gradually rectifying and channeling its predictive processes" (p. 87).

\section{Projective Practices}

The demonstration of the use of this method and its interpretive procedures is easily done by examining a type of activity that generally encourages a great deal of interpretive work: a person making sense of a magic act. Such a person is concerned with accomplishing some kind of explanation for the seemingly magical and contradictory events that the magician is performing. In general, however, just as scientists do not reject their pet theories after one or two disconfirming experiments (cf. Kuhn, 1970; Polanyi, 1974), so the observer of the magic act does not conclude that magic is being done by the performer. Some other explanation that meets the criterion of rationality in the culture is selected as an account for the observed contradictions of many basic 
assumptions about the world. Magic, sorcery, or witchcraft are rejected as viable explanations for the same reason that scientists sometimes reject alternative explanations: "for no other reason than that they are not held to be true or rational descriptions" (Polanyi, 1974, p. 72).

To simplify somewhat, say the member is attempting to choose between two constructed possible schemata for interpreting the indexical particulars of the situation, one being that magic has occurred as the performer makes an object disappear or appear in his hand, the other choice being that some sleight of hand or illusion has been done. In doing a practice referred to as projection (cf. Goodman, 1973), the member will ascertain which explanation can account for the available constructed particulars as well as which can be projected to other situations, both past and future. In the example, an explanation that talks of magic is less projectable than one that talks of sleight of hand since one is more compatible with the general body of mundane knowledge, that is, is more well entrenched than the alternative explanation. As Goodman suggests, an entrenched projection is preferred to one that lacks such entrenchment, since the entrenched explanation is conceived as higher in factual value or has a greater probability of being found to be inductively true. This facticity, which stems from the entrenchment of the explanation, is then reflexively taken by the member to support the projectability of the inference and this attribution of projectability further attests to and strengthens the entrenchment of the projection. The reflexivity culminates in the interlocking of the projectability, facticity, and entrenchment of the realized explanation. In addition, projection also justifies the use of the projective practice. By doing the projection, the member is engaged in work with a procedure that has worked well in the past and is thus better entrenched than any other practice such as random guessing or mystical devinations. As a wellentrenched scheme, it is very consistent with the established social reality and is thus high in facticity. Lastly, each additional application of the projective method further entrenches the practice and increases the acceptance of its facticity as a demonstrably rational interpretive practice.

\section{Comparative Practices}

As Garfinkel (1967) suggests, members often achieve a sense of information and understanding by categorizing and comparing new situations with others to evaluate them as to their normal form or typification. While this rational practice is left implicit in Garfinkel's works related to the documentary method of interpretation, it is of great significance in the doing of realizations. For example, the member in coming to form a realization between some schemata must necessarily compare the schemata for compatability with the previously constructed body of relevant social knowledge. This comparison should be recognized as part of the projective procedures by which the individual makes an assessment of the degree of entrenchment and degree of 
facticity. In addition, the member will also determine the degree to which a given scheme of interpretation is consistent with additional occurrrences of relevance to the scheme by employing the comparative practice. For example, to return to our magician, say that the member constructs an account of the performance that proposes the series of acts are merely "sleeve tricks," such that the magician is extracting objects from his sleeve rather than from the air. This scheme, at this point, is consistent with the accomplished indexical particulars of the situation and provides a thematic key to interpret previously inconsistent particulars, as well as forms a gloss for prospective particulars. However, if on the next occurrence the magician performs a trick that totally eliminates the possibility that the object was extracted from the sleeve (such as seeming to make a large object appear), then irrespective of the reflexivity of the interpretive work, the magnitude of the discrepancy between the phenomenon and the scheme will be too great to reconcile. The assumption that the magician is doing sleeve tricks must be discarded and an alternative account must be done. As Kuhn (1970) has described the process of revolution in scientific thought, the old paradigm must be finally rejected for a new one which has been waiting ready in the wings.

The comparative process involves pitting a particular explanation against other possible and viable schemata to pragmatically determine its ability to account for the indexical particulars of the situation. While the method proposes that complex interrelationships between particulars and the degree to which they support a given scheme are quite usual, several techniques frequently comprise the comparative practice. For example, our observer's explanation of the magic act depends upon the possibility that the object could be hidden in the performers sleeve until "magically" produced. However, the occurence of a trick that ran counter to this original assumption (such as apparently creating an elephant or doing the previously witnessed trick while shirtless and coatless) would necessarily lead to a reappraisal of the sufficiency of the created scheme. While additional reflexive work could be done to gloss over the observed inconsistency, such as concluding that while the sleeve was used on previous tricks it was not used in the present case, in some situations it may be easier and more rational to discard the embraced assumption and select a new account of the accomplished indexical particulars. It is this process of release and replacement that is accomplished by the doing of the method of realization and the projective and comparative procedures.

\section{A DEMONSTRATION}

To exemplify the method of realization and its procedures, a demonstrational study (Garfinkel, 1967) was conducted making use of a magic "trick." Six male and 7 female students in an introductory psychology course volunteered to participate in an experiment entitled "Information Proces- 
sing." Upon entering a small room in the Psychology Building, subjects were seated and asked to read a description of their role in the project. This description stated that they would be acting as observers to "offer as many explanations as possible that can account for the action" which the experimenter was about to perform. The instructions emphasized that the subject was to "think out loud as much as possible, so that if you do think of an explanation, do not hesitate to express it, no matter how awkward or illconceived it may be."

At this moment the experimenter placed three, large, colored dots (blue, yellow, and green) on the table before the subject and asked the subject to select a color and think about the selection momentarily. The experimenter then stated, "Now I want you to tell me what color you selected, and I will indicate to you that I knew what color you would pick ahead of time." The experimenter then demonstrated that he knew in advance which color would be picked by directing the subject's attention to a certain object in the room depending upon which color was selected. If green, then the experimenter asked them to turn over the green card. On its reverse side was printed the message, "You picked this one." If the subject picked the yellow one, then the experimenter retrieved a message from the envelope which had contained the colored cards that stated "You picked the Yellow." Lastly, if the subject picked the blue one, then an ink pen was taken from a pen and pencil holder that was unobtrusively placed on the table; inscribed on its side was the message, "You picked Blue." The subject then was asked to explain what he/she had seen, and the subject's interaction with the experimenter was recorded. At no time during the session did the experimenter refer to the action as a "trick."

The essence of the magical act, then, was to direct the subject's attention away from the indicators of the other colors toward the single indicator of his chosen color. In addition, the explanation of the ruse seemed obvious to the observer. Every subject who selected the green card immediately turned over the other cards to see if the message "You picked this one," was written on the back of the blue and yellow cards as well. (In fact, on the back side of these cards was the message, "No, you picked the Green card.") Each subject who selected the blue card wanted to examine all the pens in the holder to see if there was one for each color. Lastly, nearly every subject who selected the yellow card asked to see the contents of the envelope to determine if a card for each color was inside (only one subject did not; her interaction with the experimenter is presented below). Unfortunately for the subjects, all these explanations they had done were not compatible with the particulars of their investigations, and they were forced to perform additional interpretive work. The following three transcripts of the conversations between the experimenter (E) and the subjects (S) describe the problem they faced more adequately than a summary. 
TRANSCRIPT ONE (MALE)

[He selected the blue card, and was shown the pen with the message, "You picked Blue.'] Experimenter: Now, how did I do it? Obviously, if I've got that pen then I must have known...

Subject: What do the other pens say on them, I mean, does it make a difference?

E: What do you mean?

S: You have three pens, and each one matches one of the cards.

E: No [shows the pens]. Well, I guess that means I didn't do it that way. What explanations do we have left?

S: It has a black mark [a speck on the card the subject noticed], you put it in the middle, plus it's bolder.

E: What if I told you I never missed anyone's selection. Can you think of an explanation of how I might do it?

S: I don't know... brainwaves or something [laughter].

E: How about magic?

S: No, I don't believe in that.

E: How come?

S: I just don't.

E: Even though we've ruled out all other explanations?

S: Well, there's a probability that it could happen, but you know, the chance of that happening that many times, well, you know...there is a chance of it though.

E: Of it being magic?

S: No, No. Of you getting it, guessing it each time. You know, like one in 10,000.

E: But there is not a chance that I could have done it using magic?

S: What do you mean by "magic"?

E: Magic, that I could predict somehow.

S: No, I don't believe that.

TransCript Two (MALE)

[He selected the blue card, and was shown the pen with the message, "You picked Blue.']

E: Now, explain it to me.

S: Well, obviously there is no preguessing on your part; I mean I told you which one I picked and you knew what pen it was. Is that what you mean?

E: Yeah, well..., do you think there is a message written on each pen?

S: Of some sort, somewhere or another.

E: You can look at these if you want [shows the pens]. Do you have another explanation?

S: Well, guess the majority of people will pick this middle color because of its position and color.

E: What if I told you I have never missed anyone's selection? That I have $100 \%$ accuracy on this?

S: I would say its kind of improbable.

E: Well, I have never missed this, by the way.

S: Really? You have never missed this?

E: No, never. Would you say that indicates your explanation is probably not right?

S: Yes.

E: Do you have any other explanations? Well, one explanation that you haven't mentioned yet could be that I just used magic to do this.

S: I don't believe in it.

E: Why not? We have ruled out all other explanations, and we have this one left. Why not?

S: I don't know. I just don't believe in that. There has got to be some other way you did it.

E: Is there anything I could have done that would convince you it was magic?

S: No. 
Transcript Three (Female)

[She selected the yellow card, and read the message "You picked the Yellow."]

E: Now, could you please explain this to me?

S: Well, either it was ESP which I don't think it was, or chances are it was just luck that you had this card in there because all the circles are the same, colored. I mean there are equal chances that I will pick one. So it was probably just luck that you had this card in there.

E: How would you go about checking the explanation that it was luck?

S: You would have to try the same thing over several times and see how many times you put the right card in there.

E: Do you have any other explanations besides those two? You don't think it was ESP?

S: No.

E: How come?

S: Well, you only had this one card in there, so it was like it was prearranged. It wasn't like it was because I thought of it or that you read my mind, it was more like you had just decided before we even started what I would pick. You just tried to predict instead of reading my mind.

E: So you think it was probably luck.

S: Yes.

E: Any other explanation?

S: I don't see how else you could have done it.

E: What if I had told you that I have done this, say 20 times, and I've never missed it. I've always been able to correctly indicate the selection.

S: Well, you've got to consider the laws of probability... I can't see any real explanation for it, I mean, any other kind of real evidence for it besides that [referring to luck].

E: How about if I told you that is not correct, that I don't use luck, that its not just a chance thing, that $I$ always get this right.

E: You mean that there is some other explanation for it? Um, I wouldn't believe you 'cause I can't see how else you could have done it unless you want to tell me how else you did it.

E: How about if I told you that I used magic to do it? What kind of explanation is that?

S: I don't believe in magic so I don't think-_-I won't accept that. I don't think that is valid.

E: Even if you can't explain it any other way?

$\mathrm{S}$ : It would have to be something that you can prove. If you just say that it is magic that is not proving it because magic, unless it is explained, is probably just a trick on the person. And if you just say, "Well, it's magic," it's not really explaining why it happened.

The reactions of subjects in this simple demonstration followed a basic pattern which reflected their attempts to make sense of the experimenter's performance. First, all employed the comparative practice in an attempt to verify the power of the "obvious" explanation of the action. Their investigations, however, generated particulars which did not support their explanation and necessitated the creation of additional explanations. These explanations, however, were less projectable than the first and were far less satisfying for the subjects. They tended to offer several, and were not willing to defend any of them from the experimenter's attack. One account, the wellentrenched but ambiguous explanation calling on luck, was preferred by 
many subjects, even when the experimenter claimed that he never missed in his forecast. Subjects clearly favored this explanation or not knowing at all to the suggestion that the experimenter had actually used some type of magic. Apparently, the subjects did not consider an explanation based on magic to be projectable to future or past situations, entrenched, or high in facticity. In fact, subjects preferred to believe that they did not understand how the trick was done, but that they would if certain particulars were revealed to them, rather than assume that magic had been performed. In the words of one subject: "Even when something is magic, it's not really magic."

\section{CONCLUSION}

The interpretation and suggested method and procedures presented in this discussion are designed to account for some of the previously mentioned rational activities of reality creators, as well as the mundane features of the reality which is done. The method of realization, taken with the projective and comparative procedures, suggests and specifies some of the work that members do in making sense of the particulars of their world. The proposed practices, because of their previous, though implicit, mention in other sources (e.g., Garfinkel, 1967; Goodman, 1973; Kuhn, 1970; Polanyi, 1962, 1974), are happily fairly well entrenched already; thus, they can be granted some degree of facticity within an ethnomethodological framework. In addition, they seem to be quite compatible with the documentary method and its procedures, and illuminate in greater detail the interpretive work of members. The suggestion of these methods, while admittedly a tentative and exploratory step toward the enumeration of additional procedures which underlie members' doings, does provide an additional dimension of description relevant to both the features and creation of mundane reality.

\section{ACKNOWLEDGMENTS}

The author would like to thank D. Tuthill for his comments on an earlier draft of the manuscript, and W. Sanders for his comments, training, and suggestion of the activity used in the demonstration.

\section{REFERENCES}

Bloor, M. Bishop Berkeley and the adenotonsillectomy enigma: An exploration of variation in the social construction of medical disposals. Sociology, London: Oxford Univ. Press, 1976, $10,43-61$.

Circourel, A. Cognitive Sociology. London: MacMillan, 1973.

Garfinkel, H. A conception of and experiments with "trust" as a condition of concerted stable actions. In O. J. Harvey (Ed.), Motivation and social interaction. New York: Ronald Press, 1963. 
Garfinkel, H. Studies in ethnomethodology. New York: Prentice-Hall, 1967.

Goodman, N. Fact, fiction, and forecast. New York: Bobbs-Merrill, 1973.

Heider, F. The psychology of interpersonal relations. New York: Wiley, 1958.

Kuhn, T. S. The structure of scientific revolutions. Chicago: Univ. of Chicago Press, 1970.

Leiter, K. C. W. An ethnomethodological background assumption: The documentary method and the interpretive procedures. Paper presented at the Southwestern Social Science Association, Dallas, Texas, April, 1976.

Mehan, H., \& Wood, H. The reality of ethnomethodology. New York: Wiley 1975.

Neisser, U. Cognitive Psychology. Englewood Cliffs, N.J.: Prentice-Hall, 1967.

Polanyi, M. Personal knowledge. Chicago: Univ. of Chicago Press, 1962.

Polanyi, M. Scientific thought and social reality. New York: International Universities Press, 1974.

Schutz, A. The problem of rationality in the social world. Economica, London: Economica, 1953, 10. 